\title{
Rise of obesity incidence in ChNPP accident survivors is related to abnormal secretion of $\alpha$-melanotropin
}

\author{
O.V. Kaminskyi, D.Y. Afanasyev, O.M. Kovalenko, L.P. Derevyanko, \\ N.P. Atamanuk, K.O. Vakoluk
}

National Research Center for Radiation Medicine of NAMS of Ukraine, Kiev, Ukraine

\section{Background}

The Chernobyl NPP accident (USSR/ Ukraine) in 1986 and Fukushima NPP accident (Japan) in 2011 are still the most serious wide-scale man-made disasters in human history because of both high amounts of persons exposed and values of radiation exposure doses. Massive radioactive release and fallout followed both accidents. Wide range of radioactive isotopes were released some having high affinity to hormone-producing tissues including ones in the cerebral endocrine structures. And both accidents are now the point if concern in research and radiation protection field.

The radiation dose was absorbed partially within initial days and months upon the accident in Chernobyl and then for several years, that's why it is difficult to estimate both dose value and its unfavorable biological and health impact. Today the Chernobyl NPP accident is not over but has evolved into the long-term fourth phase.

\section{Results}

Higher incidence of borderline obesity $37 \%\left(X^{2}\right.$ Yates $\left.=4.22 ; p=0.04\right)$ and of primary obesity - 32.5\% $\left(X^{2}\right.$ Yates $\left.=8.5 ; p=0.004\right)$ was found in the ChNPP accident survivors vs. persons in the control group (31.1\% and $24.6 \%$ respectively). Normal body mass was more prevalent in the general population $(39.3 \% ; p=0.002)$.
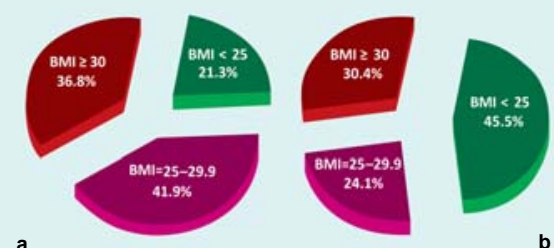

Body mass index $\left(\mathrm{kg} / \mathrm{m}^{2}\right)$ in Chernobyl NPP accident survivors (a) and in the control group (b)
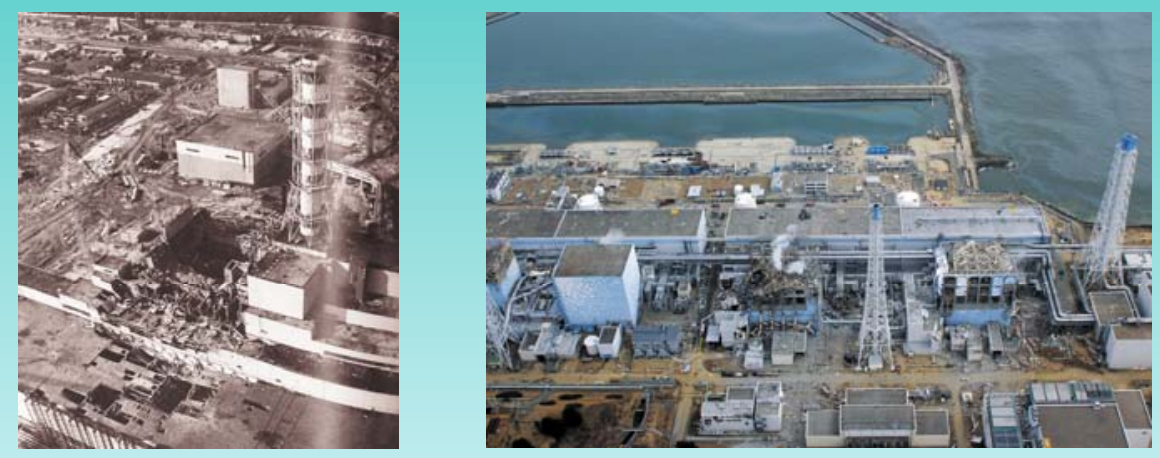

\section{Study objective}

Estimation of pre-obesity and obesity incidence in various population groups of survivors of the Chernobyl NPP accident and of possible impact of ionizing radiation on body mass.

\section{Subjects and Methods}

The Chernobyl NPP accident survivors (emergency workers of 1986-1987 period and evacuees from the 30-kilometer Chernobyl exclusion zone) aged 30-65 $(43.25 \pm 0.37)$ at the time of accident.

Estimation of pre-obesity and obesity incidence in various population groups of survivors of the Chernobyl NPP accident and of possible impact of ionizing radiation on body mass.

The subgroup analysis indicated that primary obesity was more often found in ChNPP accident emergency workers of the so-called "non-iodine period" of 1986$1987(47.3 \%)$ and of "iodine period" of 1986 (34.2\%).

For the first time there was revealed a new abnormal way of a reaction on radiation namely - the "blunted" protective response of the physiological increase of a-MSH secretion along with body mass index elevation normally preventing further growth of adipose tissue. There is no increase of $\alpha-\mathrm{MSH}$ secretion or even there is a hormone deficiency in most survivors of the ChNPP accident having borderline obesity or obesity.

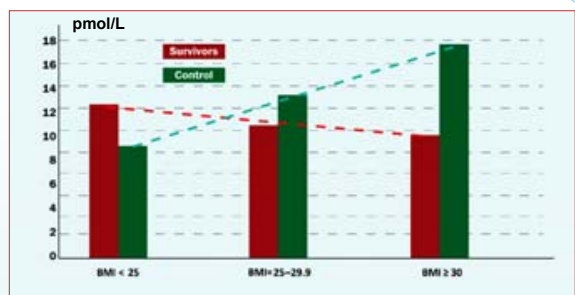

Abnormal elevation of pituitary $\alpha-M S H$ concentration under body mass increase in survivors of the Chernobyl NPP accident (emergency workers and evacuees)

Decrease of $\mathrm{a}-\mathrm{MSH}$ concentration in Chernobyl emergency workers under the increase of external radiation dose can be considered as a marker of radiation brain damage. Thus a-MSH can be considered as a sensitive marker of radiation impact which deficiency of synthesis leads to disorder of pathways preventing further body mass increase.

\section{Conclusion}

Received data indicate to the increased risk of borderline obesity and obesity after the prolonged exposure to radiation in moderate doses. The mentioned risk is stipulated by disorders in melanocortin system resulting in a-MSH deficiency at the background of obesity that can be considered as a marker of such an abnormality. 